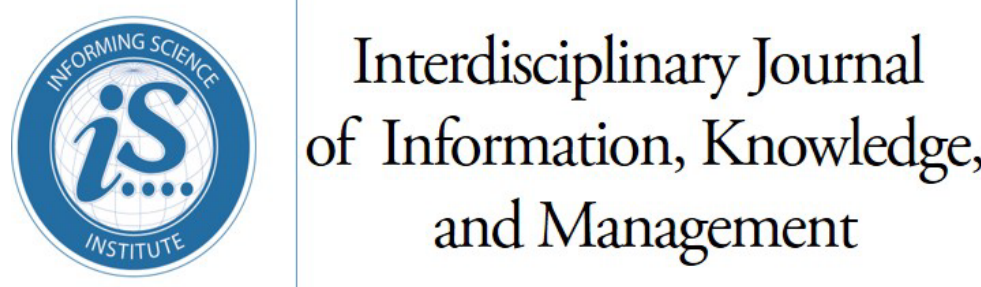

An Official Publication

of the Informing Science Institute

InformingScience.org

IJIKM.org

\title{
Volume 15, 2020 \\ SOCIAL MEDIA USE AND ITS EFFECT ON KNOWLEDGE SHARING: EVIDENCE FROM PUBLIC ORGANISATIONS IN Delta StaTe, Nigeria

$\begin{array}{ll}\text { Rev. Fr. Anthony Igwe } & \begin{array}{l}\text { University of Nigeria, Enugu Campus, Anthonyigwe121@gmail.com } \\ \text { Enugu, Nigeria }\end{array} \\ \text { Uzoma Heman Ononye* } & \begin{array}{l}\text { University of Nigeria, Enugu Campus, Ononye.uz@gmail.com } \\ \text { Enugu, Nigeria }\end{array} \\ \text { * Corresponding author } & \end{array}$

ABSTRACT

Aim/Purpose

This study investigates social media use and its effect on knowledge sharing. Based on the review of related literature, we hypothesised that social media use has a significant effect on outward and inward knowledge sharing.

Background

While the notion of social media use in work organisations has been progressively developed, empirical studies linking social media to the context of knowledge sharing have only begun to emerge. Even so, literature on social media use and its impact on public organisation is still tentative and remains a developing area.

Methodology

The partial least square method was utilised in testing of hypotheses with data collected from 103 employees, who by virtue of their position and job function(s) interface with the public for the purpose of sharing knowledge via the social media space.

Contribution

The study made contributions to the social knowledge management literature in two ways. First, the study developed a research model that links social media use to the two distinct dimensions of knowledge sharing. Second, the study provides a quantitative approach, where statistical techniques were applied to validate the social media use and knowledge sharing link.

Findings Statistically, the public organisations utilise social media partly for knowledge sharing, with its effect being significant on outward knowledge sharing and insignificant on inward knowledge sharing. This indicates that social media were deployed mainly for information dissemination "outward knowledge sharing" and not for stakeholders' feedback and interaction "inward knowledge sharing".

Accepting Editor Jon K. Webber | Received: October 24, 2019| Revised: January 9, January 24, January 31, February 4, 2020 | Accepted: February 5, 2020.

Cite as: Igwe, A., \& Ononye, U. H. (2020). Social media use and its effect on knowledge sharing: evidence from public organisations in Delta State, Nigeria. Interdisciplinary Journal of Information, Knowledge, and Management, 15, 25-37. https://doi.org/10.28945/4503

(CC BY-NC 4.0) This article is licensed to you under a Creative Commons Attribution-NonCommercial 4.0 International License. When you copy and redistribute this paper in full or in part, you need to provide proper attribution to it to ensure that others can later locate this work (and to ensure that others do not accuse you of plagiarism). You may (and we encourage you to) adapt, remix, transform, and build upon the material for any non-commercial purposes. This license does not permit you to use this material for commercial purposes. 
Recommendations Public organisations should develop a policy framework and guidelines for social media use to encourage the full use of this technology to inform and interact with stakeholders. It is important for this policy document to adopt best practices regarding interactive spaces so that both knowledge sharing dimensions manifest themselves in social media communications. Second, it is necessary to carry out staff training for the professional use of this technology for knowledge sharing.

Future Research Future studies may extend to public organisations in other geographical locations around Nigeria. It will be useful for studies to provide an international perspective by sampling public organisations from different countries or by comparing and contrasting the findings of other studies, specifically those from other countries. A longitudinal study should be encouraged to detect advancement or development with regards to the subject matter over a period of time.

Keywords

social media, knowledge sharing, outward knowledge sharing, inward knowledge sharing, public organisation

\section{INTRODUCTION}

Social media tools are progressively changing the communication landscape by allowing individuals to connect, share, and collaborate with others on the internet. The capacity to enhance social and network centric processes has made its use expand exponentially over the past decade (Ononye \& Igwe, 2017). With the dramatic development of social media tools in forms, numbers, and functionality, organisations are increasingly adopting these revolutionary corporate tools in changing how individuals network and collaborate in the workplace (Ahmed, Ahmad, Ahmad, \& Zakaria, 2018). The widespread adoption of social media tools has led to calls for more use in the public sector to inform, serve, and interact with stakeholders. Today, stakeholders in the social media space are expecting public organisations to connect and interact with them using the same channels to better value creation and delivery (Karakiza, 2014; Omar, Stockdale, \& Scheepers, 2014; Stieglitz \& Dang-Xuan, 2012). This call has been heard, at least in Nigeria, where some public organisations have moved to utilise the features of social media in extending their reach and engagement with stakeholders. For instance, in 2011, 2015, and 2019, the Independent National Electoral Commission (INEC) used social media tools - Facebook and Twitter - to provide a check to the credibility of the national and state elections through situation reports from the electorates and other stakeholders at polling stations. The Occupy Nigeria Protest in 2012, driven partly by the social media following a price increment in price of premium motor spirit (PMS), also provided the impetus for government and its organisations to use social media as a facet of e-governance to understand the demands of stakeholders and freely discuss issues relevant to public good without restrictions of time and space (Danbatta, 2017; Olayiwola, 2014; Ononye \& Igwe, 2017).

Ononye and Igwe (2017) argue that the use of social media for knowledge sharing in the Nigerian public sector is not a common practice. For organisations that do adopt it, it is a far cry from what is expected in an interactive and collaborative space. The rigid and complex procedures of public bureaucracy can result in the use of social media within existing frameworks, in which public organisations use social media mainly for information dissemination. Consequently, the full depth and breadth of knowledge may never be realised because these organisations have not fully embraced social media's capacity to mobilise stakeholders for collective action (Omar et al., 2014). However, one may argue that the utilisation of social media for knowledge sharing is still at early stages of progress, when we consider recent attempts by the Nigerian Communication Commission (NCC) and National Information Technology Development Agency (NITDA) to advance the adoption and use of social media in the Nigerian public sector through their respective framework and guidelines (National Information Technology Development Agency [NITDA], 2019; Nigerian Communication Commission 
[NCC], 2019). As the Internet and its ubiquitous applications continue to extend globally, an increasing number of governments and their agencies will embrace social media as one of the major mechanisms to interact with the public (Ayanso \& Moyers, 2012). In this line, public organisations in Nigeria have begun to use social media, many of which make known their presence in the social media space through their official social media accounts. The growing relevance of knowledge sharing using social media implies a fundamental change in the traditional knowledge sharing channels, which has usually been exclusively initiated and managed by specific actors in the public sector (Stieglitz \& Dang-Xuan, 2012).

The primal appeal of using social media is that it allows public organisations to engage stakeholders as knowledge partners in the management of challenges that affect their regulatory roles and interventions in different policy areas. Social media tools have the potential to change a wide variety of management practices (e.g., knowledge sharing) and also can reengineer the old model of public sector as they offer numerous knowledge-related opportunities to better strategy, practice, and performance (Campbell, Lambright, \& Wells, 2014). Meijer and Torenvlied (2014) state that social media enable public organisations to build new communication networks for transparent, participative, and collaborative interactions with stakeholders. It is seen as an information equaliser allowing access to public information to stakeholders who, in the past, would not have this access (Westerman, Spence, \& Van Der Heide, 2014).

Social media are designed to be help organisations engage stakeholders in true multi-way conversations and interactions (Heldman, Schindelar, \& Weaver, 2013). This is to say that these tools can help the public organisations reconfigure existing knowledge sharing paradigms as marked by mass information dissemination to include stakeholders' engagement and feedback. Owing to this fact, there are two possible knowledge sharing dimensions from external organisational use of social media: (1) outward knowledge sharing, and (2) inward knowledge sharing. Outward knowledge sharing involves the broadcast of information about organisational policies and activities. In contrast, inward knowledge sharing involves soliciting and obtaining feedback from stakeholders whose views are deemed helpful and relevant (Carim \& Warwick, 2013; Omar et al., 2014; Ononye \& Igwe, 2017).

While the notion of social media use in work organisations has been progressively developed, empirical studies linking social media to the context of knowledge sharing have only begun to emerge (See Ahmed et al., 2018; Naeem, 2019). Even so, literature on social media use and its impact on public organisation is still tentative and remains a developing area (Sivarajah, Irani, \& Weerakkody, 2015), which is in part attributed to the unique challenges and idiosyncrasies of public organisations (Hisham, Sharif, Troshani, \& Davidson, 2015). The argument that bureaucratic communication does not fit current social media communications may be compelling, but it has never been empirically tested or explored (Meijer \& Torenvlied, 2014). Ononye and Igwe (2017) argue that the use of social media to facilitate stakeholders' engagement remains an issue to be explored. It represents a novel and challenging idea yet to be an integral part of the official governance policy of any government or its agencies (Sivarajah, et al., 2015). Jukić and Merlak (2017) argue that governmental agencies are still experimenting with social media as a channel for communication with stakeholders. Drawing on these arguments, there is need for more evidence to understand how social media use facilitates knowledge sharing and a need to empirically investigate this phenomenon to inform better use of social media in the public sector. Next, this study will discuss the concepts of social media use and knowledge sharing and establish the linkages between these concepts based on related literature. It will also present the methodology adopted, results, and main conclusion. 


\section{LITERATURE REVIEW}

\section{SOCIAL MEDIA USE}

Social media is generally seen as a group of web-based applications and technologies that enable users to create and exchange a multitude of user-generated content with each other as well as build social networks with aim of knowing and learning (Ahmed et al., 2018). Social media technologies integrate dialogic communications in public organisations relationship with citizens, businesses, and other organisations (Jukić \& Merlak, 2017), making interactions with stakeholders more visible and actionable (Ononye \& Igwe, 2017). There are several popular social media applications, with Facebook, Twitter, and Instagram widely used for content creation, dissemination, and use in Nigeria (NITDA, 2019; NCC, 2019). These applications are taking an ever-growing part in conversations and debates on the actions of government (Ahmed et al., 2018). Social media users generate contents and voice their feelings on issues that affect them. This may be the reason why many of them have being ranked among the most visited sites in Nigeria (NCC, 2019). With the ever-increasing number of Internet users and, by extension, social media users in Nigeria, public organisations (such as the Central Bank of Nigeria, the Nigerian Army, the Nigeria Police Force, the Economic and Financial Crimes Commission, and the Federal Road Safety Corps) have begun to recognise the need to exploit this trend by setting up social media accounts to connect with critical stakeholders in a collaborative paradigm. To ensure these applications remain value-driven, public organisations are beginning to develop intricate social media policies and strategies that will enable them effectively take part in collaborative relationships. These policies and strategies allow handlers the freedom to utilise social media under a controlled and measured environment, where relevant and valuable ideas are shared about how to approach different organisational and societal problems (Jukić \& Merlak, 2017; Meijer \& Torenvlied, 2014). However, the social media space presents a dual challenge: (1) the overload of information that constantly requires organising and (2) the lack of assurance on contents quality, which necessitates the continual monitoring of credibility on the part of the public organisations.

\section{KNOWLEDGE SHARING}

Naeem (2019) argues that the objectives of social media and knowledge sharing are considered similar because both support collaborative interactions for the exchange of context-specific knowledge, skills, and experience. In this line, social media support processes or features that are part of the knowledge management system of an organisation. There are two knowledge sharing dimensions from social media use, which allows a more inclusive two-way communication model. These dimensions are outward knowledge sharing and inward knowledge sharing (AndohQuainoo \& AnnorAntwi, 2015; Gunawong, 2015; Lee \& VanDyke, 2015; Murphy, 2010; Pérez-González, TriguerosPreciado, \& Popa, 2017). The active involvement of these distinct dimensions allows public organisations to engage in social and collaborative interactions for the exchange of knowledge across organisational boundaries. Outward knowledge sharing connotes communications with external constituents that have a defined relationship or communication with the organisation (Ononye \& Igwe, 2017). This dimension seeks to publish information to stakeholders on issues or concerns that are topical and of interest to their policy or priority areas. It raises stakeholders' awareness of organisational actions, thereby, allowing them to develop their personal knowledge (Campbell et al., 2014). Though outward knowledge sharing is the most obvious function to consider when utilising the social media, it gives little consideration to the public perceptions and interpretations of the published contents.

In contrast, inward knowledge sharing occurs when public organisations interact or consult their external constituents to get them to share their experiences, insights, and informed opinions on a range of issues (Wen, 2011). The aims of inward knowledge sharing are to learn from the spontaneous feedback through the comment functions and develop community-based partnership by providing a convenient channel for public expression (Gregson, Brownlee, Playforth, \& Bimbe, 2015; Munro, 
2014). This is important for public organisations because it gives them the opportunity to listen to the public and identify contentious or misunderstood decisions or policies, which they may then adjust or clarify to aid collective understanding and action. Knowing what the public thinks on policy options is a crucial precursor for targeted policy interventions or broad, long-term initiatives. Concurring with these views, Elving and Postma (2017) state that social media tools are transformational in their ability to provide public organisations with instant feedback and new workflow perspectives and should create immediate dialogue through an interactive forum. However, in dialogic communication, these distinct knowledge sharing dimensions are active processes in the sense that public organisations transfer knowledge or consult on issues relevant to public needs and interest. The integration of both dimensions of knowledge sharing strengthens existing social capital and reinforces the flow of new knowledge.

\section{RECENT STUDIES}

Omar et al. (2014) argued that the local government councils in Australia use social media with no clear aim to interact with stakeholders and are more motivated to have a presence in and experiment with social media. Campbell et al. (2014) argued that the county departments in south-central New York State used social media to raise stakeholders' awareness of organisational activities. Using data from U.S. federal government science agencies, Lee and VanDyke (2015) argued that, despite calls to adopt an interactive model, social media is still being used for information dissemination rather than engagement. Gunawong (2015) found out that Thai public agencies have largely neglected social media as new tools to increase their communications with the public. Thai public agencies simply disseminate news to the extent it is related to the agencies via social media - Facebook. This situation may be due to the lack of official policies on open government in the Thai administrative context. Jukić and Merlak (2017) argued that social media are mainly used for one-way interaction and that there is a lack of formal policies guiding social media usage in public administration in Slovenia. Concurring with these views, Ononye and Igwe (2017) argued that the local government councils in Delta State, Nigeria are yet to utilise the interactive and collaborative features of social media in encouraging stakeholders' cooperation, engagement, and feedback. Social media, specifically Facebook, was used for outward knowledge sharing but not for inward knowledge sharing. It is instructive to mention that adherence to the deficit model of knowledge sharing limits the opportunities social media tools provide to help public organisations understand deeper levels of engagement. The limited engagement reduces the ability of public organisations to learn or gain new knowledge helpful to their operations, such as reports of infrastructural problems, criminal activities, or conditions during periods of emergency (AndohQuainoo \& Annor-Antwi, 2015; Campbell et al., 2014; Lu, Zhang, \& Fan, 2015). Pérez-González et al. (2017) suggested that organisations could benefit from social media by using them for acquiring information from stakeholders. The purposive inflows of knowledge enable an organisation to look beyond its boundaries and enrich its own knowledge base. Thus, it ensures a better understanding of changing societal needs as well as reinforces abilities to adapt to these changes.

\section{Research gaps}

Drawing on the arguments above, the studies reviewed adopted a qualitative approach, which is a necessary foundation for building literature and theory. But there is a dearth of empirical works that made use of the quantitative approach in arriving at the findings, leaving generalisation as an open issue for research. In order to build on recent research, this study adopts the quantitative approach, where statistical techniques can be applied to further validate the link between social media use and knowledge sharing. Second, empirical evidence from the African country context, Nigeria in particular, is somewhat lacking in literature. Only one study - Ononye and Igwe (2017) - was found to be relevant to Nigeria. The dearth of recent studies shows that it remains a developing area in need of more empirical validation (Ahmed et al., 2018; Meijer \& Torenvlied, 2014; Naeem, 2019; Sivarajah et al., 2015). These gaps led to the initial motivation for this study. In addition, there seems to be an 
agreement that social media usage influences knowledge sharing in some ways, with the use being noticeable on outward knowledge sharing and not for inward knowledge sharing. In other words, social media is used as a conduit for agency-produced information dissemination rather than for stimulating stakeholders' engagement and feedback. The theory of media affordance contends that social media facilitate certain knowledge sharing practices and therefore, the use of social media may lead to a change in knowledge sharing pattern (Meijer \& Torenvlied, 2014). With the progressive use of social media tools, we anticipate that there can be a more holistic approach as public organisations gain experience and become more informed on the benefits to be gained from increased interactivity and connectivity. This recognition can set the stage for the development of formal standard operating rules for the deployment and use of social media for not only outward knowledge sharing but inward knowledge sharing via their official social media accounts (Jukić \& Merlak, 2017).

Taking into account previous research in the field, the following research hypotheses were formulated, and represented in a research model in Figure 1: (1) social media use has a significant effect on outward knowledge sharing, (2) social media use has a significant effect on inward knowledge sharing.

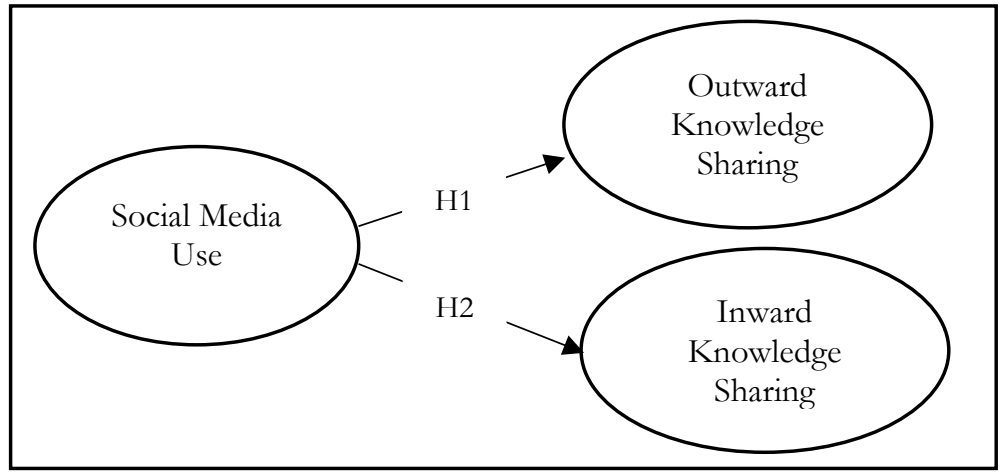

Figure 1. Hypothesised Research Model

\section{RESEARCH METHODS}

The quantitative approach was used to operationalise the constructs, with data obtained using the survey method. The study was delimited to organisations, i.e., ministries, departments and agencies, in Delta State, Nigeria with state ownership structure because of the proximity of the researchers to these organisations and, also, to enable focused observations. The target respondents for this survey were purposively drawn from employees who by virtue of their position and job function(s) interface with the public for the purpose of sharing knowledge via the social media space. Besides, the selected respondents can convey the true situation on the ground in relation to the topic of interest due to their familiarity with knowledge sharing activities across the different social media platforms. As such, a total of 113 employees were identified and contacted for participation from the different ministries, departments, and agencies in Delta State, Nigeria with job titles such as executive assistant on media, senior special assistant on media, special assistant on new media, personal aide on media, new media aide, media aide, and public relations officer. The questionnaire administration was conducted in person between the months of August and September 2019. During this period, efforts were made to follow-up with the respondents through reminders on three occasions to ensure a high response rate to the survey instrument. It took the respondents approximately five minutes to complete the questionnaire. Nevertheless, 10 out of the 113 questionnaires were returned uncompleted, indicating a non-response rate of 8.8 percent. Thus, only 103 completed questionnaires were analysed to derive the results. The 103 valid responses were considered adequate and above the recommendation of Anderson and Gerbing (1988), where the minimum sample size of 100 is required to achieve stable estimation results in structural equation modelling. 
The measurement items in the questionnaire were adapted from previous investigations to make them more suitable for the current research setting. Social media use and knowledge sharing dimensions items were taken and adapted from Teo and Lee (2016) and Pérez-González et al. (2017). The items were rated on a five-point Likert scale, ranging from 1 - never, 2 - rarely, 3 - sometimes, 4 often, to 5 - always. The respondents were asked to indicate the frequency level to the questions on social media use and knowledge sharing practices. Since the respondents were required to pick the appropriate responses from a fixed scale, the responses contained no outliers (See Appendix for the measurement items for the constructs). Prior to the questionnaire administration, the research instrument was pre-tested on 10 of the target respondents through random sampling in June 2019. Subsequently, some questions were modified from the pre-test feedback before inclusion in the final draft. Because modifications have been made in line with the findings from the pilot study, the data collected could be deemed flawed or inaccurate compared to the data from the final sample (Van Teijlingen \& Hundley, 2001). Therefore, the study found it necessary not to include the responses from the pilot study in the final sample to avoid contamination of the results. The construct reliability of the research instrument was ascertained using the Cronbach's alpha test, and the resulting values (Social media use $\alpha=0.861$, outward knowledge sharing $\alpha=0.914$ and inward knowledge sharing $\alpha=0.827$ ) were above the minimum acceptable value of 0.70 , indicating high internal consistency. The reliability test was done with the aid of the SPSS 20.0.

The study utilised the Partial Least Square (PLS) path modelling for data and hypotheses testing. PLS is a multivariate analytical method used to explain the psychometric properties of the outer model and estimate the parameters of the inner model simultaneously. The responses were encoded and entered into the SPSS 20.0 spreadsheet and converted to a Comma Separated Values File (.csv), then analysed using SmartPLS 3.2.7. The two-step estimation procedure as suggested by Anderson and Gerbing (1988) was followed to ensure the measurement items are valid and reliable before attempting to establish the relationship among the latent constructs. The first step is the confirmatory factor analysis (CFA) of the outer model, that is, instrument validation. The reflective measurement model was assessed with five criteria: factor loading (FL), t-test, composite reliability (CR), average variance extracted (AVE), and Fornell-Larcker criterion for discriminant validity. The second step involves the estimation of the inner model for hypothesis testing. These results are described next.

\section{RESULTS}

The demographic characteristics from the data collected shows that the ages of respondents vary between 20-29 (9 percent), 30-39 (32 percent), 40-49 (55 percent) and 50-59 (4 percent). Out of the 103 responses used in this study, males represented 67 percent and females represented 33 percent of the total responses. The majority of the respondents had a graduate degree ( 88 percent), 9 percent had a post graduate degree and 3 percent had a professional certificate. The respondents had a mean work experience of 10.7 years, indicating sufficient amount of practical knowledge on issues involving social media use for knowledge sharing. From the responses, the most used social media application for information dissemination, and public engagement and feedback is Facebook (69 percent). Instagram (25 percent) and Twitter ( 6 percent) were also utilised but do not have widespread popularity and usage as Facebook.

Following the steps previously mentioned in the research methods, the analysis of results should begin with the evaluation of the outer model of this study. Thus, the confirmatory factor analysis (CFA) was performed to establish the relationship between the latent constructs and their respective indicators. The results of the outer model, as shown in Table 1, revealed that the FLs of all the measurement indicators were within the acceptable range of $>0.707$ as recommended by Chin (1998) and Hair, Hult, Ringle, and Sarstedt (2013). Social media use indicators ranged from $0.810-0.895$, outward knowledge sharing indicators ranged from $0.835-0.926$, and inward knowledge sharing indicators ranged from $0.777-0.941$. Thus, all the measurement indicators correlated significantly with their underlying constructs and were retained in the outer model. The t-values of all the measurement 
indicators were $>1.96$, indicating that the indicators were statistically significant to the underlying constructs. Social media use ranged from 13.669 - 30.127, outward knowledge sharing ranged from $13.971-28.540$, and inward knowledge sharing $2.597-3.869$. The CR test conducted showed a mean coefficient value of 0.9 , which is considered above the minimum limit of $>0.7$ for a high reliability of the research instrument. The AVE values were above the acceptable value of 0.50 as recommended by Henseler, Ringle, and Sinkovics (2009), suggesting good convergent validity. The AVE values (bolded diagonal values in the correlation matrix in Table 1) were greater than the inter-construct correlations (off diagonal values in the correlation matrix), indicating discriminant validity of constructs was achieved.

Table 1. Factor Loading, T-values, Reliability and Validity

\begin{tabular}{|c|c|c|c|c|c|c|c|}
\hline Latent Constructs & FLs & T-values & CR & AVE & \multicolumn{3}{|c|}{ Discriminant Validity } \\
\hline Social Media Use & & & 0.900 & 0.751 & 0.866 & & \\
\hline SMU1 & 0.810 & 13.699 & & & & & \\
\hline SMU2 & 0.891 & 39.127 & & & & & \\
\hline SMU3 & 0.895 & 23.868 & & & & & \\
\hline Outward Knowledge Sharing & & & 0.915 & 0.782 & 0.428 & 0.884 & \\
\hline OKS4 & 0.835 & 13.971 & & & & & \\
\hline OKS5 & 0.889 & 20.803 & & & & & \\
\hline OKS6 & 0.926 & 28.540 & & & & & \\
\hline Inward Knowledge Sharing & & & 0.885 & 0.721 & 0.154 & 0.172 & 0.849 \\
\hline IKS7 & 0.777 & 2.610 & & & & & \\
\hline IKS8 & 0.941 & 3.869 & & & & & \\
\hline IKS9 & 0.821 & 3.597 & & & & & \\
\hline
\end{tabular}

Note: FLs= Factor Loadings, CR= Composite Reliability, AVE = Average Variance Extracted

Overall, the outer model has acceptable values for all the quality criteria, and therefore, provides evidence that supports the suitability of the outer model for the current study. However, after the determination of the quality of the outer model in step one, the inner (or structural) model was created to evaluate the significance of the hypothesised relationships. The inner model was evaluated based on beta values, $\mathrm{t}$-values and $\mathrm{p}$-values. The results of the analysis are summarised in Table 2.

Table 2. Inner Model Estimates

\begin{tabular}{llllll}
\hline Hypotheses & Path (Relationship) & Beta & T-value & P-value & Support \\
\hline 1 & $\begin{array}{l}\text { Social Media Use } \rightarrow \text { Outward } \\
\text { Knowledge Sharing }\end{array}$ & 0.428 & 4.105 & 0.000 & Yes \\
2 & $\begin{array}{l}\text { Social Media Use } \rightarrow \text { Inward } \\
\text { Knowledge Sharing }\end{array}$ & 0.154 & 1.162 & 0.245 & No
\end{tabular}

Note: $\mathrm{p}<0.05$ 
Table 2 shows the inner model estimates, where the beta values indicate the direct relationship between the independent construct and dependent constructs; t-values indicate the statistical importance of the hypothesised relationship to the inner model; and the p-values represent the significance of the results. From the estimates, social media use was found to have a significant effect on outward knowledge sharing $(\beta=0.428,4.105>1.96, \mathrm{p}<0.05)$. Furthermore, social media use was found to have an insignificant effect on inward knowledge sharing $(\beta=0.154,1.162<1.96, p>$ 0.05). The results provided statistical support for hypothesis one and no support for hypothesis two. Figure 2 illustrates the developed research model, which was evaluated and proved by hypotheses testing.

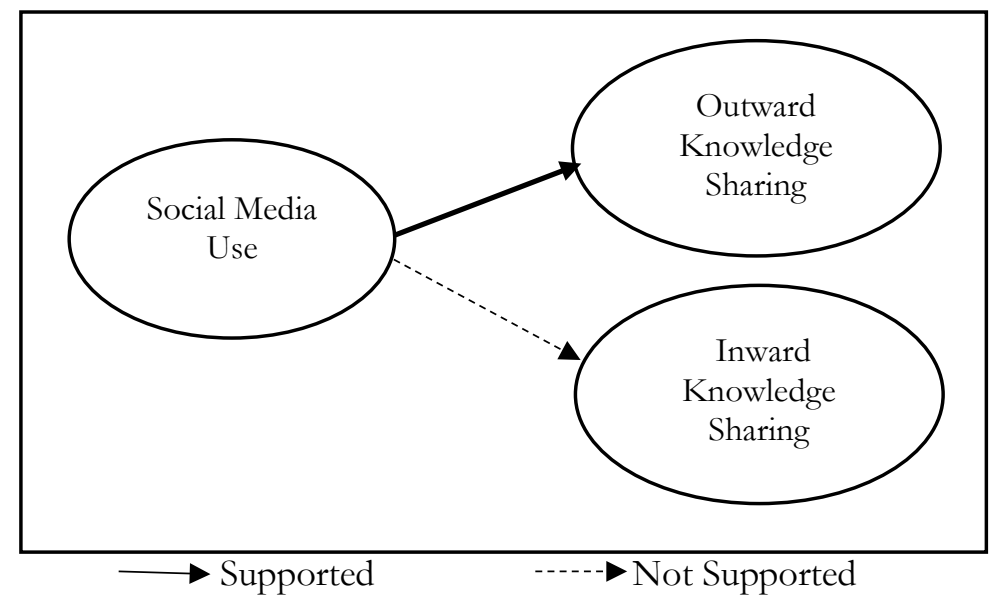

Figure 2. The Developed Research Model

\section{CONCLUSIONS, LIMITATIONS, AND FUTURE RESEARCH}

This study provided an extended investigation of the effects of social media use on the two distinct knowledge sharing dimensions in the public organisations in Delta State, Nigeria. The results obtained are interesting for both theory and practice. In theory, the research model demonstrated that social media use has significant effects on outward knowledge sharing and not on inward knowledge sharing. These results support past scholarship (Andoh-Quainoo \& Annor-Antwi, 2015; Campbell et al., 2014; Carim \& Warwick, 2013; Lee \& VanDyke, 2015; Lu et al., 2015; Omar et al., 2014; Ononye \& Igwe, 2017) that reported the same one-sided knowledge sharing approach. The results contradict the assumption of the theory of media affordance that the use of new media - social media may lead to a change in knowledge sharing pattern (Meijer \& Torenvlied, 2014). Still, social media were deployed mainly for information dissemination ("outward knowledge sharing") and not for stakeholders' feedback and interaction ("inward knowledge sharing"). Owing to this fact, public organisations may find it difficult to reconfigure an existing communication model to a less bureaucratic model that better fits the communication demands of the knowledge society. This situation creates adaptation problems because limited stakeholders' engagement reduced the capacity to learn or gain new knowledge critical to organisational operations (Campbell et al., 2014). The truism is that the inability to maintain deeper levels of engagement with stakeholders may lead to policy actions not truly representing the realities of time and trends. Inward knowledge sharing is meant to form part of the social media strategy of public organisations in Nigeria (NITDA, 2019), but adherence to the bureaucratic model of communication shows that there may be no clear policy framework and guidelines for institutionalising a knowledge sharing paradigm that includes stakeholders' engagement (Gunawong, 2015; Jukić \& Merlak, 2017).

Despite the relations these organisations have with stakeholders, engaging in true dialogue with them using social media tools runs contrary to existing knowledge sharing framework - centralised and vertical communications. The derivation of real value from robust and collaborative conversations 
requires public organisations not to use social media at the superficial level. There should be a shift in perspective to accommodate some ceding of control and empowerment of stakeholders to work towards an outcome of shared meaning. On the other hand, the results may also be attributed to the notion that knowledge sharing dimensions in these organisations are organised in a separate manner, with different channels used for inward and outward knowledge sharing (Meijer \& Torenvlied, 2014). Ononye and Igwe (2017) argue that public bureaucracy places a major constraint on the type of information shared on social media, with preference still given to traditional communication channels, such as town hall meetings, to inform and discuss real societal issues. As such, government communication is still dominated by the use of mass media channels, irrespective of the obvious demerits of one-sided, non-interactive communications with the public (Murphy, 2010). Furthermore, social media is not recognised as a formal channel of communication, thus, issues raised still require a formal notification via traditional means (such as written letters, face-to-face contacts, and telephone conversations) before any action can be taken. One may argue that the information shared through this channel is often unclear and, sometimes, deemed inaccurate. This is because with the increasing amount of information available through social media applications, the gatekeeping function seems to shift from public organisations to stakeholder - consumers. To avoid running into misinformation and misguided actions, these organisations usually assess the credibility or authenticity of information through traditional means (Westerman et al., 2014). However, it is apt to mention that social media engagement lends a human element to conversations with the public. It helps public organisations not to be seen as tone deaf or insensitive to the concerns and needs of the public (Heldman et al., 2013).

The results hold practical implications for public managers and public organisations. The main point is that the use of social media can serve as springboards for furthering the knowledge sharing paradigm of public organisations. Perhaps, if public organisations acknowledge stakeholders' contributions or inputs to the policy making process, the inward knowledge sharing function can be activated to instigate discussions in areas where there are strong stakeholders' touch points. This should be a critical aspect from strategy. Importantly, conversations in social media about governance issues are happening at an alarming rate whether we choose to participate and not. Since the number of social media users continues to grow, this situation can present priceless opportunities to solicit and gather insights for targeted and timely policy interventions (Heldman et al., 2013). Therefore, the core argument for the use of social media is that the communication model in bureaucratic organisations no longer fits the dynamic and complex nature of the knowledge society and needs to be reconfigured to maintain its effectiveness and legitimacy (Meijer \& Torenvlied, 2014).

Based on the results, this study proposes that public organisations should develop a policy framework and guidelines for social media use to encourage the full use of this technology to inform and interact with stakeholders. It is important for this policy document to adopt best practices regarding interactive spaces so that both knowledge sharing dimensions manifest themselves in social media communications. This in turn ensures a steady flow of context-specific, credible knowledge to inform targeted policy interventions as well as broad, long term initiatives. Public organisations could rely on the framework and guidelines prepared by NITDA (2019) and NCC (2019) in achieving this objective. Second, as social media becomes widely used, it is necessary to carry out staff training to ensure the professional use of this technology for knowledge sharing.

This study had some limitations. First, the dearth of studies in the Nigerian public sector context made the review of empirical studies difficult. However, similar studies conducted in developed countries were utilised to situate this study within the tradition of inquiry and context of related studies. Second, the research was restricted to a specific state, that is, Delta State in Nigeria, which limited the number of potential respondents from similar work setting in other Nigerian States. However, the issues stated in this study may likely have applicable value to the public organisations in other states. 
Future studies may extend to public organisations in other geographical locations around Nigeria because there might be differences in the responses to those of this study. It will be useful for studies to provide an international perspective by sampling public organisations from different countries or comparing and contrasting the findings of other studies, specifically those from other countries. Additionally, a longitudinal study should be encouraged to detect advancement or development with regards to the subject matter over a period of time.

\section{REFERENCES}

Ahmed, Y. A., Ahmad, M. N., Ahmad, N., \& Zakaria, N. H. (2018). Social media for knowledge sharing: A systematic literature review. Telematics and Informatics, 37, 72-112. https://doi.org/10.1016/j.tele. 2018.01.015

Anderson, C. J. \& Gerbing, W. D. (1988). Structural equation modelling in practice: A review and recommended two-step approach. Psychological Bulletin, 103(3), 411-423. https://doi.org/10.1037/00332909.103.3.411

Andoh-Quainoo, L., \& Annor-Antwi, P. (2015). The use of social media in public relations: A case of Facebook in the Ghanaian financial services industry. New Media and Mass Communication, 41(1), 37-47. https://doi:10.7176/NMMC.vol4137-47

Ayanso, A., \& Moyers, D. (2012). The role of social media in the public sector: Opportunities and challenges. In K. Kloby \& M. D'Agostino (Eds.), Citizens 2.0: Public and Governmental Interaction through Web 2.0 Technologies (pp. 1 - 22). Hershey, PA: IGI Global. https://doi.org/10.4018/978-1-4666-0318-9.ch001

Campbell, A. D., Lambright, T. K.. \& Wells, J. C. (2014). Looking for friends, fans, and followers? Social media use in public and non-profit human services. Public Administration Review, 74(5), 655-663. https://doi.org/10.1111/puar.12261

Carim, L., \& Warwick, C. (2013). Use of social media for corporate communications by research funding organisations in the UK. Public Relations Review, 39(2013), 521-525. https://doi.org/10.1016/i.pubrev.2013.08.006

Chin, W. W. (1998). The partial least squares approach to structural equation modelling. In G. A. Marcoulides (Ed.). Modern methods for business research (pp. 295-336). New Jersey: Erlbaum.

Danbatta, U. (2017, June 17). Role of social media in the social, economic and political development of Nigeria. The Premium Times. Retrieved from http://www.premiumtims.ng.com

Elving, J. L. W. \& Postma, M. R. (2017). Social media: The dialogue myth? How organizations use social media for stakeholder dialogue, How Strategic Communication Shapes V alue and Innovation in Society (Advances in Public relations and Communication Management, 2, 123-141. https://doi.org/10.1108/S2398-391420170000002011

Gregson, J., Brownlee, M. J., Playforth, R., \& Bimbe, N. (2015). The future of knowledge sharing in a digital age: Exploring impacts and policy implications for development. England: Institute of Development Studies.

Gunawong, P. (2015). Open government and social media: A focus on transparency. Social Science Computer Review, 35(5), 587-598. https://doi.org/10.1177/0894439314560685

Hair, J. F., Hult, G. T. M., Ringle, C., \& Sarstedt, M. (2013). A primer on partial least squares structural equation modelling (PLS-SEM). Thousand Oaks, CA: Sage Publications. https://doi.org/10.3926/oss.37

Heldman A. B., Schindelar, J., \& Weaver, J. B. (2013). Social media engagement and public health communication: implications for public health organizations being truly "social". Public Health Reviews, 35(13). https://doi.org/10.1007/BF03391698

Henseler, J., Ringle, C. M., \& Sinkovics, R. R. (2009). The use of partial least squares path modelling in international marketing. Advances in International Marketing, 20 (2009), 277-319. https://doi.org/10.1108/S14747979(2009)0000020014

Hisham, M., Sharif, M., Troshani, I., \& Davidson, R. (2015). Public sector adoption of social media. Journal of Computer Information Systems. 55(4), 53 - 56. https://doi.org/10.1080/08874417.2015.11645787

Jukić, T., \& Merlak, M. (2017). The use of social networking sites in public administration: The case of Slovenia. The Electronic Journal of e-Government, 15(1), 2 -18. Available online at www.ejeg.com 
Social Media Use and its Effect on Knowledge Sharing

Karakiza, M. (2014). The impact of social media in the public sector. Procedia - Social and Behavioural Sciences, 175(2015), 384-392. https://doi.org/10.1016/j.sbspro.2015.01.1214

Lee, M. N., \& VanDyke, S. M. (2015). Set it and forget it: The one-way use of social media by government agencies communicating science. Science Communication, 37(4), 533-541. https://doi.org/10.1177/1075547015588600

Lu, B., Zhang, S., \& Fan, W. (2015). Social representations of social media use in government: An analysis of Chinese government microblogging from citizens' perspective. Social Science Computer Review, 34(4), 416-436. https://doi.org/10.1177/0894439315595222

Meijer, A. J., \& Torenvlied, R. (2014). Social media and the new organisation of government communications: An empirical analysis of Twitter usage by Dutch Police. American Review of Public Administration. 46(2), $143-$ 161. https://doi.org/10.1177/0275074014551381

Munro, L. (2014). The dynamics of business communication: A look at social media use in the workplace. Honors Theses. Paper 2491

Muphy, G. D. (2010). Using Web 2.0 tools to facilitate knowledge transfer in complex organizational environments: ICOMS Asset Management Conference. Available at www.researchgate.net

Naeem, M. (2019). Uncovering the role of social media and cross-platform applications as tools for knowledge sharing. VINE Journal of Information and Knowledge Management Systems, 49 (3), 257 - 276. https://doi.org/10.1108/VJIKMS-01-2019-0001

National Information Technology Development Agency (2019). Framework and guidelines for the use of social media platforms in public organisations. Retrieved from www.nitda.gov.ng

Nigerian Communication Commission (2019). Technical framework for the use of social media networks in Nigeria. Retrieved from https://www.ncc.gov.ng

Olayiwola, V. O. (2014). Decoding the potency of Web 2.0 in Nigeria. International Journal of Politics and Good Governance. 5(5), 1-14.

Omar, K., Stockdale, R., \& Scheepers, H. (2014). Social media use in local government: An Australian perspective. International Journal of Public Administration, 37(10), 666-675. https://doi.org/10.1080/01900692.2014.903270

Ononye, U. H., \& Igwe, A. (2017). The utilisation of Facebook for knowledge sharing in selected local government councils in Delta State, Nigeria. Interdisciplinary Journal of Information, Knowledge, and Management, 12, 269-282. https://doi.org/10.28945/3854

Pérez-González, D., Trigueros-Preciado, S., \& Popa, S. (2017). Social media technologies' use for the competitive information and knowledge sharing, and its effects on industrial SMEs' innovation. Information Systems Management, 34(3), 291-301. https://doi.org/10.1080/10580530.2017.1330007

Sivarajah, U., Irani, Z., \& Weerakkody, V. (2015). Evaluating the use and impact of Web 2.0 technologies in local government. Government Information Quarterly, 32(2015), 473-487. https://doi.org/10.1016/j.giq.2015.06.004

Stieglitz, S., \& Dang-Xuan, L. (2012). Social media and political communication: A social media analytics framework. Soc. Netw. Anal. Min., 3(4), 1277-1291. https://doi.org/10.1007/s13278-012-0079-3

Teo, W. J. S., \& Lee, C. S. (2016). Sharing brings happiness? Effects of sharing in social media among adult users. In A. Morishima, A. Rauber, \& C. Liew (Eds.), Digital libraries: Knowledge, information and data in an open access society, (pp. 351-365). Cham: Springer. https://doi.org/10.1007/978-3-319-49304-6 39

Van Teijlingen, R. E., \& Hundley, V. (2001). The importance of pilot studies. Social Research update, 35. Available at sru.soc.surrey.ac.uk/SRU35.html

Wen, T. (2011). Achieving knowledge sharing outcomes through the activation of social capital in virtual communities: Evidence from Chinese online social network communities. Unpublished Doctoral Thesis. City University of Hong Kong, Hong Kong. 
Westerman, D., Spence, R. P., \& Van Der Heide, B. (2014). Social media as information source: Recency of updates and credibility of information. Journal of Computer-Mediated Communication, 19(2), 171-183. https://doi.org/10.1111/jcc4.12041

\section{APPENDIX}

Indicate your frequency level to the following questions on social media use in your organisation How often do you...

1. ...use social media to share information with the public?

2. ...provide status or profile updates on your social media page(s)?

3. ...reply comments or questions on your social media page(s)?

Indicate your frequency level to the following questions on social media use for outward knowledge sharing.

How often do you...

1. ...share ideas and thoughts on specific topics or issues?

2. ...publish information to sensitise stakeholders on policies and programmes?

3. ...provide updates to keep stakeholders informed about operational activities?

Indicate your frequency level to the following questions on social media use for inward knowledge sharing.

How often do you...

1. ...encourage the public to share any information on key policy areas?

2. ...capture stakeholders' opinions and views about our policies or actions?

3. ...identify new changes in stakeholders' needs?

\section{BIOGRAPHIES}

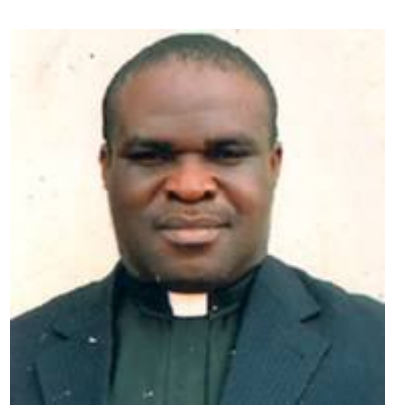

Rev. Fr. Anthony Igwe is a doctoral candidate in the Institute of Development Studies, University of Nigeria, Enugu, Nigeria. He has Ph.Ds. in Management, Philosophy and Economics respectively. His research interests are in the areas of knowledge management, conflict and diversity management, and hospital management. He is currently a Roman Catholic Priest and senior lecturer in the Department of Management, Faculty of Business Administration, University of Nigeria, Enugu, Nigeria.

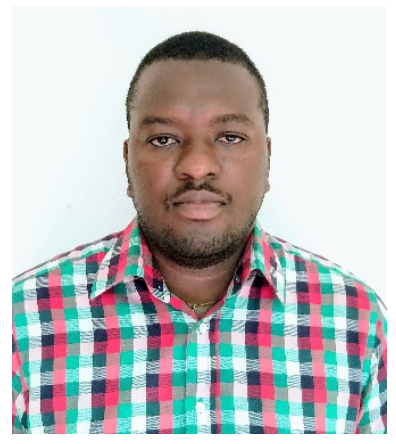

Uzoma Heman Ononye holds a Ph.D. in Management obtained from University of Nigeria, Enugu, Nigeria in 2019. His research interests are on issues centred on knowledge management, innovation management and public sector management. 